\title{
In vitro Quantitative Kinetic Study of Infectious Pancreatic Necrosis Viral Antigen by Flow Cytometry
}

\author{
Sylvia Rodríguez, M. Pilar Vilas, Carmen Gutierrez and Sara I. Pérez* \\ Centro de Investigaciones Biológicas (Consejo Superior de Investigaciones Científicas), \\ C/Velazquez 144, 28006 Madrid, Spain
}

(Received April 4, 1994)

\begin{abstract}
Infectious pancreatic necrosis virus (IPNV) was infected in CHSE-214 cells, and viral antigens in the cells stained with indirect immunofluorescence method were monitored by flow cytometer during early multiplication stage of the virus. Viral antigen could first be detected at $2 \mathrm{~h}$ post infection (p.i.), and the larger numbers of labeled CHSE-214 cells were obtained at 8 and $24 \mathrm{~h}$ p.i. in both VR-299 and Sp strains of IPNV examined. The detection method is fast and sensitive and yields quantitative results on single cell basis.
\end{abstract}

Key words : infectious pancreatic necrosis, fish virus, flow cytometry, viral antigen

Infectious pancreatic necrosis (IPN) is a serious viral disease of salmonid fish. The causative agent is a member of the family Birnaviridae and considered to be a nearly ubiquitous fish virus (Pilcher and Fryer, 1980). An outbreak of IPN may cause high mortality in susceptible salmonids of less than 6 months of age and survivors may become virus carriers, possibly for life. The most reliable and accepted method for identification of the virus is a neutralization assay using replicated viruses in cultured cells. However, this assay usually takes a long time for samples with low levels of infectivity such as the carrier samples.

Fluorescent antibody procedures have been used for many years to detect viral antigens in fish (Hetrick, 1989; Ahne, 1984). Flow cytometry (FCM) is a relatively new technique of automated cell analysis. By labelling cellular macromolecules (DNA, RNA or protein) with specific fluorescent dyes, the cell content of these macromolecules can be accurately measured, in a few microseconds. There is a broad range of applications of this technique: studies on cellular differentiation, chromosome analysis, microbiology, genetics, clinical research haematology, immunology and oncology (Shapiro, 1985; Watson, 1989). However, there are relatively few publications on virology using FCM (Lehman and Jacob-

\footnotetext{
* Author to whom correspondence should be addressed.
}

berger, 1990), the application of FCM in the study of virus of slow replication such as IPNV may be advantageous. Replication of the virus in the cell can be classified as two types, lytic and non lytic. In the former type the cell dies in a short time after exposure to the virus and viral progeny are released (permissive infection), while in the nonlytic virus infection virus may be produced continuously over a long period of time without killing the cell. In previous papers, purified leucocytes from pooled blood samples (Rodríguez et al., 1991) and sperm (Rodríguez et al., 1993) of suspected IPNV carrier rainbow trout were stained by indirect immunofluorescence and analyzed by FCM. The advantage of this method suggested its use in other fish viral infection studies.

The purpose of this work was to detect IPN viral antigens throughout the multiplication cycle in CHSE-214 cell line, using the indirect immunofluorescence stain and flow cytometry.

\section{Materials and Methods}

\section{Cells and viruses}

The CHSE-214 line was obtained from American Type Culture Collection (ATCC). The cells were grown in Minimal Essential Eagle's medium with Earle's salts (MEM, Flow) containing 100 units $/ \mathrm{m} l$ penicillin, $100 \mu \mathrm{g} / \mathrm{m} l$ streptomycin and $10 \%$ foetal 
calf serum (FCS, Flow), at $20^{\circ} \mathrm{C}$ in $80 \mathrm{~cm}^{2}$ plastic culture flasks (Costar). For the assays cells were plated onto plastic culture flasks or dishes, so that the monolayers were at $80 \%$ confluence and ready for use the next day.

Infectious pancreatic necrosis virus (IPNV) serotype $\mathrm{Sp}$ was isolated during the epizootic in rainbow trout in Spain. IPNV strain VR-299 was obtained from ATCC. Viruses were stored at $-70^{\circ} \mathrm{C}$. The infective titre of the viral stocks was $1 \times 10^{8}$ TCID $_{50} / \mathrm{ml}$.

\section{Antisera}

As a primary antibody, a polyvalent anti-IPNV serum developped in rabbit (Vilas et al., 1990) and absorbed on CHSE-214 cell monolayers was used at a final dilution of $1: 1,000$. As secondary antibody, a $1: 40$ dilution of fluorescein isothiocyanate (FITC)conjugated goat anti-rabbit IgG (Sigma) was used. As a preliminary control for specificity, a rabbit preimmune serum was employed.

\section{Flow cytometry}

Subconfluent cell monolayers growing on 6-well plates (Costar) were infected with the reference virus at a multiplicity of infection (m.o.i.) 1 and collected at different hours post infection.

Values of 5000 cells were recorded for each sample. As controls, mock-infected cells were used and stained with both first and second antibodies. Additional controls of infected cells stained with a pre-immune serum as first antibody or stained with only the second antibody, were used to measure the background fluorescence.

The flow cytometry requires analysis of individual cells. To dissociate the monolayer cultures, the medium was removed and the monolayer was gently rinsed with cold phosphate buffered saline (PBS).
The cells were then harvested, centrifuged at $300 \times g$ for $5 \mathrm{~min}$, resuspended in a small volume of PBS, and mixed with $1 \mathrm{ml}$ of cold $80 \%$ acetone for $10 \mathrm{~min}$ at $-20^{\circ} \mathrm{C}$.

After fixation the cells were resuspended, washed in PBS and stained, as follows: drops of polyvalent IPNV antiserum $(1: 1,000)$ were mixed with the cells and incubated at $20^{\circ} \mathrm{C}$ for $30 \mathrm{~min}$ to allow the antigen-antibody reaction to take place. After several washes with PBS $+2 \%$ FCS, a drop of $1: 40$ FITC conjutated goat anti-rabbit IgG was added and incubated again for $30 \mathrm{~min}$ at the same temperature. Two further centrifugations in PBS $+2 \%$ FCS were done to decrease non-specific binding and the fluorescence of the cellular suspensions was determined by flow cytometry, using an EPICS CS (Coulter) equipped with an Argon ion laser, at $488 \mathrm{~nm}$ and 299 $\mathrm{mW}$ light output, working at $700 \mathrm{~V}$.

\section{Virus titration}

Viral infectivity was determined in CHSE-214 cells growing in 96-well microtiter plates (Costar), by the end-point dilution method (Reed-Muench, 1938), incubating the infected monolayers at $19^{\circ} \mathrm{C}$.

\section{Results}

\section{Determination of threshold for immunofluorescence positive cells}

The cells stained non specifically in mock-infected cells ranged from $0.5-3.15 \%$ of total cells. Therefore, the result of flow cytometry of mock-infected cells was used to determine the specific-threshold on the immunofluorescence histogram for each experiment as shown in Figs. 1 and 2. The number of fluorescent-positive cells which are above each threshold was calculated and expressed as percentage of the total cell number.

Fig. 1. Time course of newly synthesized viral antigen of IPN virus serotype VR-299 on CHSE-214 cells infected at m.o.i. 1. The abcissa scale is divided into 256 channels. The relative frequency of cells with the corresponding fluorescence intensity to the total cell number is expressed on the ordinate scale. Uninfected control cells were included in the experiment to allow determination of the specificity threshold shown by dotted line. Numbers on the right show the percentage of fluorescence positive cells, which are above the threshold, to the total cell number.

Fig. 2. Time course of newly synthesized viral antigen of IPN virus serotype Sp on CHSE-214 cells infected at m.o.i. 1. The abcissa scale is divided into 256 channels. The relative frequency of cells with the corresponding fluorescence intensity to the total cell number is expressed on the ordinate scale. Uninfected control cells were included in the experiment to allow determination of the specificity threshold shown by dotted line. Numbers on the right show the percentage of fluorescence positive cells, which are above the threshold, to the total cells number. 


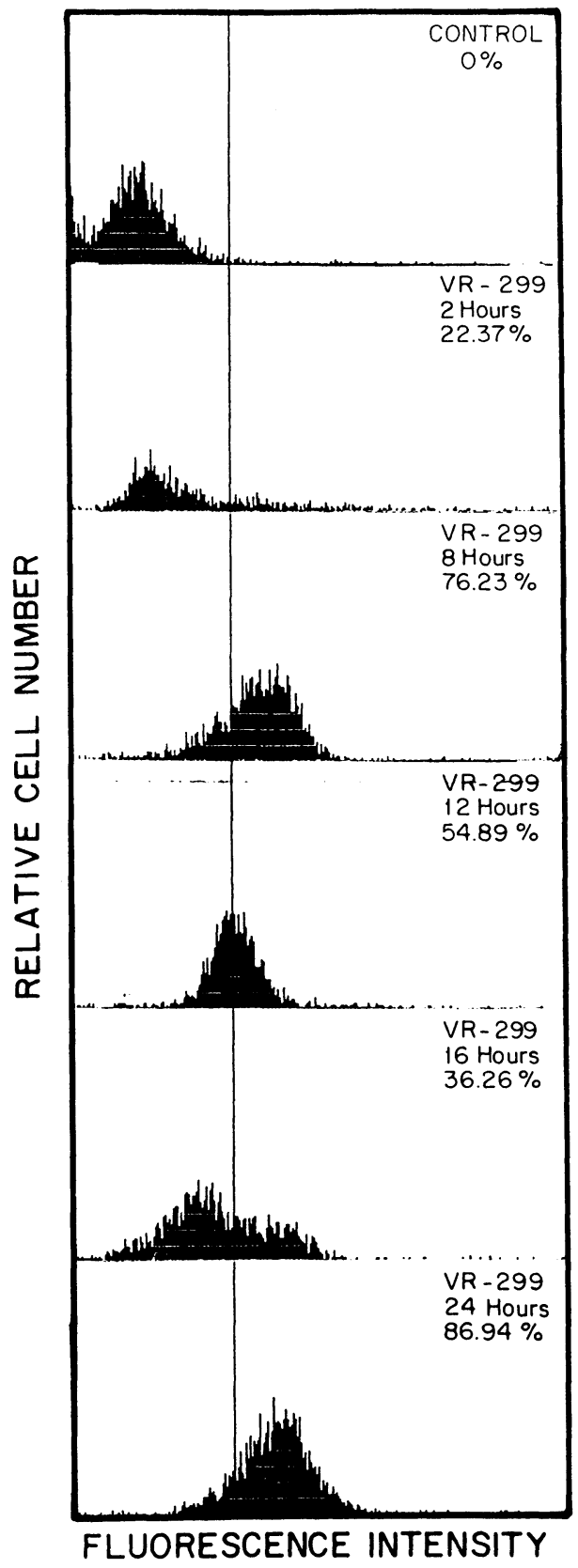

Fig. 1

Viral antigen detection using FCM

Viral antigen was first detected by flow cytometry analysis as early as $2 \mathrm{~h}$ p.i. in both IPNV VR-299 and Sp serotypes. Fluorescent cells increased in number, from 22 or $26 \%$ to $76 \%$ or $81 \%$ in the next six hours after infection (Figs. 1 and 2).

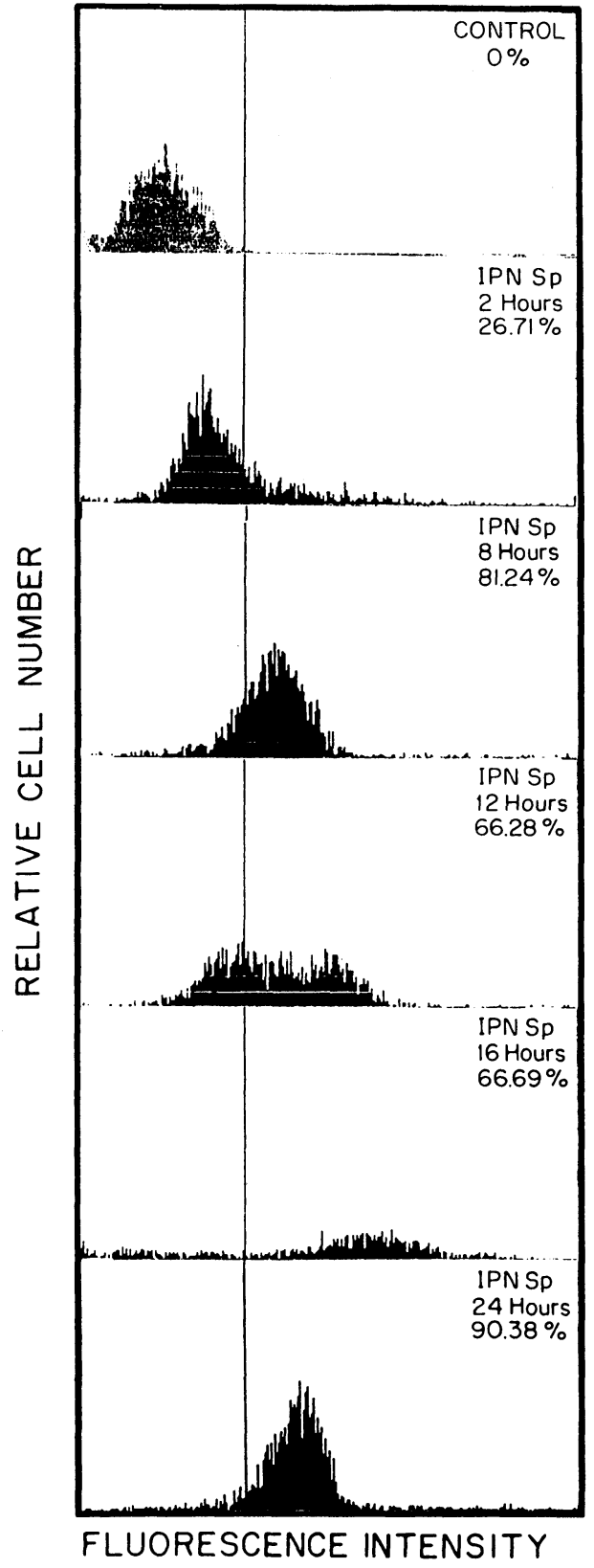

Fig. 2

The time course kinetics of IPNV serotype VR299 antigen is represented in Fig. 1. The graph shows a high level of fluorescent cells $(76.23 \%)$ at 8 h p.i. Cells examined at 12 and $16 \mathrm{~h}$ after infection demonstrated a lower percentage of positives as compared to cells examined at $8 \mathrm{~h}$. The highest occur- 


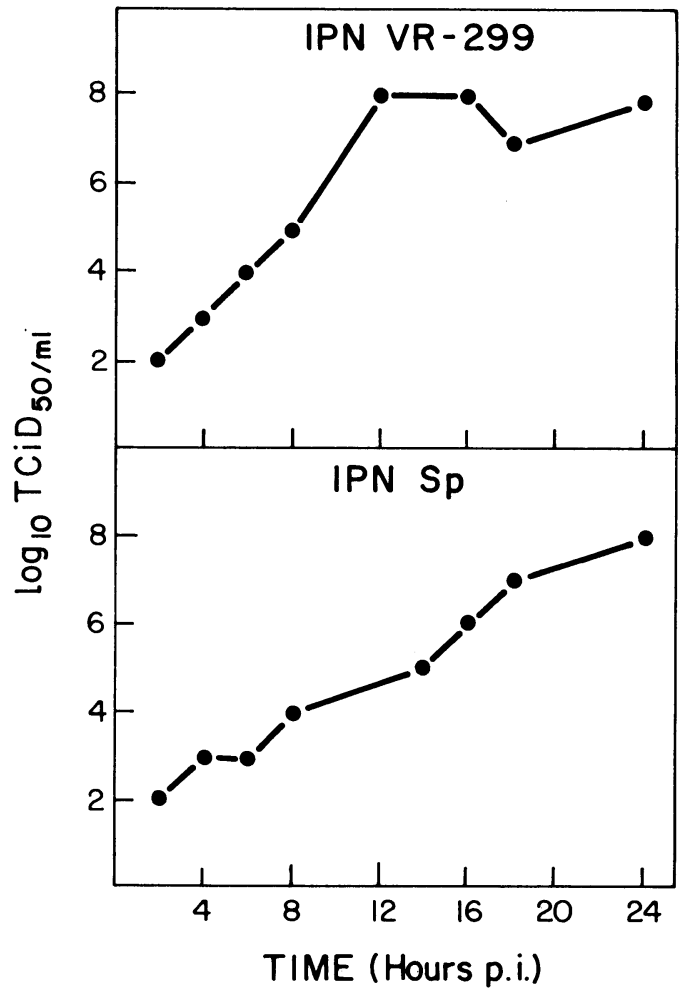

Fig. 3. Growth curves of IPN virus (serotypes VR-299 and $\mathrm{Sp}$ ) in CHSE-214 cells starting from 1 TCID $_{50}$ per cell.

rence of fluorescent cells (more than $86 \%$ ) with a sheer single peak of histogram was obtained at $24 \mathrm{~h}$ after the infection.

The profiles of IPNV Sp antigens are shown in Fig. 2. At $2 \mathrm{~h}$ the fluorescent positive cells occupied $26.71 \%$ of total cell population, and subsequently increased steadily, reflecting increased synthesis of viral antigen. The ratio of fluorescent positive cells became more than $81 \%$ of the total cell population at $8 \mathrm{~h}$ p.i., fell to 66.28 or $66.69 \%$ at 12 and $16 \mathrm{~h}$ respectively and rose again to $90.38 \%$ at $24 \mathrm{~h}$ p.i.

Change in inoculum size (m.o.i. 50) resulted in a difference in the relative number of fluorescent cells but did not affect the pattern of virus replication nor affect the time for the first detection of fluorescent cells (data not shown).

\section{Viral replication and profiles of infective titer}

The growth curves of both Sp and VR-299 strains of IPN virus determined by titration assays exhibited similar features to each other (Fig. 3) except for the delay of IPNV Sp to reach the maximum infective titer. An increase in infectious virus occurred between 5 and $12 \mathrm{~h}$ p.i. for VR-299 strain. The viral infectivity was detected in CHSE-214 cells after a latent period of $2 \mathrm{~h}$, with titers of $1 \times 10^{2} \mathrm{TCID}_{50} / \mathrm{ml}$ and reached a maximum titer of $1 \times 10^{8} \mathrm{TCID}_{50} / \mathrm{ml}$ from 12 to $14 \mathrm{~h}$, for VR-299, or 22-24 h for IPN Sp.

\section{Discussion}

The presence of IPNV is traditionally detected by cytopathic effect in tissue culture and identification by a neutralization assay. In this study, we have focused on the quantitative kinetic study of IPN viral antigen by FCM in vitro and early profiles of IPNV replication, of two strains, VR-299 and Sp. Several authors applied immunofluorescent techniques to detect IPN viral antigen by optical microscopy. Piper et al. (1973) used RTG-2 cells to study the replication of IPNV by means of the direct immunofluorescent technique. Tu et al. (1974) reported a similar assay in RTG-2 infected cells. In our study, flow cytometric analysis of infected cultured cells could detect the presence of IPNVspecific antigen as early as $2 \mathrm{~h}$ after inoculation. The larger numbers of labeled CHSE-214 cells were obtained at 8 and $24 \mathrm{~h}$ p.i. The decrease of fluorescent positive cells observed at 12 and $16 \mathrm{~h}$ may be related to the length of the infectious cycle of IPNV and the release of the antigen from the cells.

In our experiments, flow cytometry and classical end-point dilution method gave a similar result for the detection and quantification of IPNV, in respect to the sensitivity and specificity. However, the titration assay requires a second infection in cell cultures while the flow cytometry analysis can provide results in hours without the need to wait days for 2 nd viral replication in tissue culture systems.

Additionally, the latter technique may detect IPNV specific antigen in cell cultures with a latent infection with IPNV, and may be more sensitive than the standard assay, since viral specific antigen may be demonstrated in the absence of productive viral infection.

Our results demonstrate the feasibility of FCM as a quick detection and quantification of IPN viral antigens with a polyclonal antibody. Furthermore this technology may be useful in the analysis and early detection of various viral antigens, if specific monoclonal antibodies become available, and would 
provide considerable information not only on the expression of viral antigen in cells, but also on other cell-virus interactions.

\section{Acknowledgements}

This work was supported in grant-in-aids from the Comunidad de Madrid (No. C229/91) and Comisión Interministerial de Ciencia y Tecnología (MAR 910365).

We thank Pedro Lastres for technical help with the Flow cytometer, Aurelio Hurtado for the drawings and Mercedes Sánchez for technical assistance and typing the manuscript.

\section{Literature Cited}

Ahne, W. (1984): Serological techniques currently used in fish virology. In: "Developments in Biological Standardization”. (ed. by S. Karger) Basel, Switzerland, pp. 3-27.

Hetrick, F. M. (1989): Fish viruses. In "Methods for the microbiological examination of fish and shellfish". (ed. by B. Austin and D. A. Austin) John Wiley and Sons, Chichester, England, pp. 216-239.

Lehman, J. M. and J. W. Jacobberger (1990): Virus-cell interactions analyzed with flow cytometry. In "Flow cytometry and cell sorting". ed. by M. R. Melamed, T. Lindmo and M. L. Mendelsohn. Wiley-Liss Inc., pp. 623-631.
Pilcher, R. S. and J. L. Fryer (1980): The viral diseases of fish: a review through 1978. Diseases of proven viral etiology. CRC Crit. Rev. Microbiol., 7, 287-363.

Piper, D., B. L. Nicholson and J. Dunn (1973): Immunofluorescent study of the replication of infectious pancreatic necrosis virus in trout and Atlantic salmon cell cultures. Infect. Immunity, 8, 249-254.

Reed, J. and H. Muench (1938): A simple method for estimating fifty per cent endpoints. American $\mathrm{J}$. of $\mathrm{Hy}$ giene, 27, 493-497.

Rodríguez, S., P. Vilas, M. Palacios and S. Pérez (1991): Detection of infectious pancreatic necrosis in a carrier population of rainbow trout, Oncorhynchus mykiss (Richardson), by flow cytometry. J. Fish Dis., 14, 545553.

Rodríguez, S., S. Pérez and P. Vilas (1993): Flow cytometric analysis of infectious pancreatic necrosis virus attachment to fish sperm. Dis. Aquat. Org., 15, 153-156.

Shapiro, H. (1985): Flow cytometry applications: an overview. In "Practical flow cytometry", (ed. by A. R. Liss), New York, U.S.A. pp. 159-170.

Tu, K., R. Spendlove and R. Goede (1974): Immunofluorescent cell assay in infectious pancreatic necrosis virus. Appl. Microbiol., 27, 593-599.

Vilas, M. P., S. Pérez and S. Rodriguez (1990): Obtención de Sueros Inmunes en conejo frente a antigenos de virus de salmónidos. Actas del III Congreso Nacional de Acuicultura: $837-842$.

Watson, J. V. (1989): Flow cytometry in biomedical science. Nature, 325, 741-742. 